\title{
Face cooling with mist water increases cerebral blood flow during exercise: effect of changes in facial skin blood flow
}

\author{
Taiki Miyazawa ${ }^{1}$, Masahiro Horiuchi ${ }^{2}$, Daisuke Ichikawa ${ }^{2,3}$, Andrew W. Subudhi ${ }^{4}$, Jun Sugawara ${ }^{5}$ and \\ Shigehiko Ogoh ${ }^{1,2,3 *}$
}

\author{
${ }^{1}$ Center for Biomedical Engineering Research, Toyo University, Kawagoe, Japan \\ ${ }^{2}$ Research Institute of Industrial Technology, Toyo University, Kawagoe, Japan \\ ${ }^{3}$ Department of Biomedical Engineering, Toyo University, Kawagoe, Japan \\ ${ }^{4}$ Department of Biology, University of Colorado, Colorado Springs, CO, USA \\ ${ }^{5}$ Human Technology Research Institute, National Institute of Advanced Industrial Science and Technology, Tsukuba, Japan
}

\section{Edited by:}

Paul J. Fadel, University of Missouri, USA

Reviewed by:

Gary J. Hodges, The University of Alabama, USA

Kenneth H. McKeever, Rutgers,

State University of New Jersey, USA

Grant Simmons, Nike, USA

${ }^{*}$ Correspondence:

Shigehiko Ogoh, Department of

Biomedical Engineering, Toyo

University, 2100 Kujirai,

Kawagoe-shi, Saitama 350-8585,

Japan.

e-mail:ogoh@toyo.jp
Facial cooling (FC) increases cerebral blood flow (CBF) at rest and during exercise; however, the mechanism of this response remains unclear. The purpose of the present study was to test our hypothesis that $\mathrm{FC}$ causes facial vasoconstriction that diverts skin blood flow $\left(\mathrm{SkBF}_{\text {face }}\right)$ toward the middle cerebral artery (MCA $\left.V_{\text {mean }}\right)$ at rest and to a greater extent during exercise. Nine healthy young subjects (20 \pm 2 years) underwent 3 min of FC by fanning and spraying the face with a mist of cold water $\left(\sim 4^{\circ} \mathrm{C}\right)$ at rest and during steady-state exercise [heart rate (HR) of $120 \mathrm{bpm}$ ]. We focused on the difference between the averaged data acquired from $1 \mathrm{~min}$ immediately before $\mathrm{FC}$ and last $1 \mathrm{~min}$ of FC. SkBF face, MCA $V_{\text {mean }}$, and mean arterial blood pressure (MAP) were higher during exercise than at rest. As hypothesized, FC decreased $S_{k B F}$ face at rest $(-32 \pm 4 \%)$ and to a greater extent during exercise $(-64 \pm 10 \%, P=0.012)$. Although MCA $V_{\text {mean }}$ was increased by FC (Rest, $+1.4 \pm 0.5 \mathrm{~cm} / \mathrm{s}$; Exercise, $+1.4 \pm 0.6 \mathrm{~cm} / \mathrm{s}$ ), the amount of the FC-evoked changes in MCA $V_{\text {mean }}$ at rest and during exercise differed among subjects. In addition, changes in MCA $V_{\text {mean }}$ with FC did not correlate with concomitant changes in $\mathrm{SkBF}_{\text {face }}(r=0.095, P=0.709)$. MAP was also increased by FC (Rest, $+6.2 \pm 1.4 \mathrm{mmHg}$; Exercise, $+4.2 \pm 1.2 \mathrm{mmHg}$ ). These findings suggest that the $\mathrm{FC}$-induced increase in $\mathrm{CBF}$ during exercise could not be explained only by change in $S_{k B F} F_{\text {face }}$.

Keywords: middle cerebral artery blood velocity, external carotid artery, internal carotid artery, laser Doppler flowmetry, diving reflex

\section{INTRODUCTION}

Selective facial cooling (FC) increases middle cerebral artery mean blood velocity (MCA $V_{\text {mean }}$ ) at rest (Brown et al., 2003) and during exercise (Kjeld et al., 2009). Interestingly, FC is particularly effective in improving endurance exercise performance in hot environments, e.g., increasing exercise time to fatigue (Ansley et al., 2008) and lowering ratings of perceived exertion (RPE) (Mundel et al., 2007; Ansley et al., 2008). This exercise performance improvement may be related to a FC-induced increase in cerebral blood flow (CBF) which may support brain neuronal activity and metabolism and reduce central fatigue during exercise (Ide and Secher, 2000; Secher et al., 2008; Ogoh and Ainslie, 2009). Although FC elicits the diving reflex in which facial cold receptors stimulate cardiovascular changes, including bradycardia and peripheral vasoconstriction (Fagius and Sundlof, 1986; Foster and Sheel, 2005; Kinoshita et al., 2006) that may divert blood toward the brain, the underlying mechanism of a FC-induced increase in CBF remains unclear.

Anatomically, the internal carotid arteries (ICA) and external carotid arteries (ECA) branch from the common carotid artery and supply blood to brain and facial regions, respectively. Through graded dynamic exercise, ECA blood flow and facial skin blood flow $\left(\mathrm{SkBF}_{\text {face }}\right)$ gradually increases in an intensity-dependent manner (Sato et al., 2011). In addition, this increase in ECA blood flow is negatively correlated with the concomitant change in ICA blood flow (Sato et al., 2011), suggesting that an exercise-induced increase in ECA blood flow may restrict blood flow into the brain during exercise. Therefore, it is plausible that changes in ECA blood flow, i.e., $\mathrm{SkBF}_{\text {face }}$, contribute to $\mathrm{CBF}$ regulation independently of the diving reflex.

Given this background, the aim of this study was to examine whether carotid artery blood flow distribution (e.g., toward the brain and face) contributes to a FC-induced increase in CBF during exercise. We hypothesized that FC elicits a greater attenuation of $\mathrm{SkBF}_{\text {face }}$ during exercise, since a greater proportion of $\mathrm{CBF}$ may be directed to the ECA for thermoregulation, and thus we would measure a larger increase in MCA $V_{\text {mean }}$ than at rest.

\section{MATERIALS AND METHODS SUBJECTS AND ETHICAL APPROVAL}

Nine healthy men with a mean $( \pm$ SD $)$ age of $20 \pm 2$ years, height of $170 \pm 5 \mathrm{~cm}$, and body mass of $62 \pm 9 \mathrm{~kg}$ voluntarily participated in this study. Each subject provided written informed consent after all potential risks and procedures were explained. 
All experimental procedures and protocols conformed to the Declaration of Helsinki and were approved by the Institutional Review Boards of Faculty of Science Engineering, Toyo University (IRB \# 2010-R-07). None of the subjects were taking any medication that may have influenced the hemodynamic responses to exercise. All subjects were familiarized with the equipment and procedures before any experimental sessions.

\section{EXPERIMENTAL DESIGN}

On the experimental day, all subjects arrived at the laboratory in the morning $2 \mathrm{~h}$ after a light breakfast. The subjects were requested to avoid caffeinated beverages, alcohol, and strenuous physical activity for at least $24 \mathrm{~h}$ before the experiment. After the subjects were instrumented, they were seated in a semirecumbent position with a backrest and rested quietly to allow for cardiovascular stability. In the Rest trial, after 3 min data collection (i.e., baseline at rest) the face of subject was cooled for 3 min by spraying the face with a mist of cold water $\left(\sim 4^{\circ} \mathrm{C}\right)$ and fanning with fan placed $50 \mathrm{~cm}$ from the subject's face and positioned facing upwards so as to cool only the head. In the Exercise trial conducted after securing sufficient time for the recovery from physiological changes induced by the Rest trial, subjects performed $4 \mathrm{~min}$ of an incremental warm up from the initial work load of $60 \mathrm{~W}$ at a pedal rate of $60 \mathrm{revolutions} / \mathrm{min}$. The subjects were told to maintain the frequency of pedaling, and work load was increased 10-30 W every minute. With the target heart rate (HR: corresponding to $120 \mathrm{bpm}$ ) was achieved, workload was held constant $(129 \pm 12 \mathrm{~W})$ for $5 \mathrm{~min}$. After verification of steadystate-no increase in HR during the last 1 min of constant load cycling-each subject underwent 3 min of FC while continuing exercise. Subjects were instructed to breathe as normally as possible throughout the test. All the tests were carried out in a warm laboratory environment $\left(27-28^{\circ} \mathrm{C}\right)$.

\section{CARDIORESPIRATORY AND RPE MEASUREMENT}

HR was monitored using a lead II electrocardiogram (ECG). Beat-to-beat mean arterial blood pressure (MAP) was measured using finger photoplethysmography (Finometer, Finapres Medical Systems BV, Netherlands). Stroke volume (SV) and cardiac output (Q) were estimated using the Modelflow method (Beat Scope 1.1, Finapres Medical Systems BV). This method provides a reliable estimate of changes in SV and Q in healthy humans from rest to submaximal exercise (Sugawara et al., 2003). Total peripheral resistance (TPR) was calculated as MAP divided by Q. Expired air was sampled breath-by-breath and end-tidal partial pressure of carbon dioxide $\left(\mathrm{CO}_{2}\right)\left(\mathrm{P}_{\mathrm{ET}} \mathrm{CO}_{2}\right)$ was measured with a gas analyzer system (AE-310S, Minato medical science co., Osaka, Japan). In the Exercise trial, RPE were recorded using the 15-point Borg scale (Borg, 1982) immediately before FC and the end of FC.

\section{CEREBRAL BLOOD FLOW MEASUREMENT}

Mean blood flow velocity in the left middle cerebral artery (MCA $V_{\text {mean }}$ ) was obtained by transcranial Doppler ultrasonography (Multidop T, DWL, Sipplingen, Germany). A 2-MHz Doppler probe was placed over the left temporal window and fixed with an adjustable headband. Cerebrovascular resistance index (CVRi) was calculated as MAP divided by MCA $V_{\text {mean }}$.
Relative change (\%) in skin blood flow in the left forehead, approximately $3 \mathrm{~cm}$ from the midline and just above the supraorbital ridge $\left(\mathrm{SkBF}_{\text {face }}\right)$, was measured by using laser Doppler flowmetry (ALF21, Advance, Japan).

\section{TEMPERATURE MEASUREMENT}

Skin temperature was measured using thermistors (LT-ST08-12, Gram Co., Japan) placed on the center of the forehead $\left(\mathrm{T}_{\text {face }}\right)$, the right side of the upper arm $\left(\mathrm{T}_{\text {arm }}\right)$, chest $\left(\mathrm{T}_{\text {chest }}\right)$, thigh $\left(\mathrm{T}_{\text {thigh }}\right)$, and leg $\left(\mathrm{T}_{\text {leg }}\right)$. Mean skin temperature $\left(\mathrm{T}_{\mathrm{sk}}\right)$ was calculated from the body surface area distribution and thermal sensitivity of each skin area using the following formula, which was proposed by Ramanathan (1964):

$$
\mathrm{T}_{\text {sk }}=0.3 \times\left(\mathrm{T}_{\text {arm }}+\mathrm{T}_{\text {chest }}\right)+0.2 \times\left(\mathrm{T}_{\text {thigh }}+\mathrm{T}_{\text {leg }}\right)
$$

\section{DATA ANALYSIS}

All measurement data were sampled continuously at $1 \mathrm{kHz}$ using analog-to-digital converter (PowerLab, AD Instruments, Milford, MA) interfaced with a computer. Baseline data were obtained by averaging across $1 \mathrm{~min}$ immediately before $\mathrm{FC}$ at rest (i.e., baseline at rest) and from $4^{\text {th }}$ to $5^{\text {th }}$ min of exercise at constant workload (i.e., baseline during exercise). Averaged data were also acquired from $2^{\text {nd }}$ to $3^{\text {rd }} \mathrm{min}$ of facial cooling at rest (i.e., FC at rest) and during exercise (i.e., FC during exercise).

\section{STATISTICS}

Statistical analysis was performed using SigmaStat 3.5 software (Systat Software Inc., CA, USA). Following confirmation of distribution normality using Shapiro Wilk $W$ tests, data were analyzed using a Two-Way (Condition: Baseline and FC) $\times($ State: Rest and Exercise) repeated measures analysis of variance (ANOVA) with post-hoc Tukey's test. Student's paired $t$-tests were used to analyze influence of rest and exercise for the FC-induced changes of physiological parameters. Correlation coefficients were obtained to determine the relation between $\mathrm{FC}$-induced changes in $\mathrm{SkBF}_{\text {face }}$ and MCA $V_{\text {mean }}$. Data are expressed as mean \pm S.E.M. with significance for all two-tailed tests set at $P<0.05$.

\section{RESULTS}

Overall $\mathrm{T}_{\mathrm{sk}}$ was significantly increased during exercise, but FC did not change $T_{\text {sk }}$ at rest or during exercise. In contrast, $T_{\text {face }}$ was decreased (Rest, $-6.2 \pm 0.3^{\circ} \mathrm{C}$; Exercise, $-6.9 \pm 0.3^{\circ} \mathrm{C}$ ), indicating that body parts other than face were not affected by FC (Table 1).

During exercise MCA $V_{\text {mean }}, \mathrm{SkBF}_{\text {face }}, \mathrm{MAP}, \mathrm{HR}, \mathrm{SV}$, and $\mathrm{Q}$ were increased, whereas TPR was decreased and CVRi was

Table 1 | Skin temperature responses.

\begin{tabular}{llllll}
\hline & \multicolumn{2}{c}{ Rest } & & \multicolumn{2}{c}{ Exercise } \\
\cline { 2 - 3 } \cline { 5 - 6 } & Baseline & FC & & Baseline & FC \\
\hline $\mathrm{T}_{\text {face }}$ & $34.6 \pm 0.2$ & $28.5 \pm 0.4^{*}$ & & $35.6 \pm 0.2^{\dagger}$ & $28.7 \pm 0.3^{*}$ \\
$\mathrm{~T}_{\text {sk }}$ & $33.9 \pm 0.2$ & $33.8 \pm 0.2$ & & $34.8 \pm 0.2^{\dagger}$ & $34.7 \pm 0.2^{\dagger}$ \\
\hline
\end{tabular}

Values are means \pm S.E.M.; $T_{\text {face }}$, forehead skin temperature; $T_{\text {sk, }}$, mean skin temperature. ${ }^{*} P<0.05$ different from baseline. ${ }^{\dagger} P<0.05$ different from Rest. 
Table 2 | Hemodynamic and ventilatory responses and RPE.

\begin{tabular}{|c|c|c|c|c|}
\hline \multirow[t]{2}{*}{ Parameter } & \multicolumn{2}{|c|}{ Rest } & \multicolumn{2}{|c|}{ Exercise } \\
\hline & Baseline & FC & Baseline & FC \\
\hline MCA $V_{\text {mean }}, \mathrm{cm} / \mathrm{s}$ & $53 \pm 3$ & $55 \pm 3^{*}$ & $58 \pm 4^{\dagger}$ & $60 \pm 4^{* \dagger}$ \\
\hline $\mathrm{SkBF}_{\text {face }}, \%$ & $0 \pm 0$ & $-32 \pm 4^{*}$ & $132 \pm 43^{\dagger}$ & $68 \pm 36^{* \dagger}$ \\
\hline $\mathrm{MAP}, \mathrm{mmHg}$ & $87 \pm 3$ & $93 \pm 3^{*}$ & $101 \pm 2^{\dagger}$ & $105 \pm 3^{* \dagger}$ \\
\hline $\mathrm{HR}, \mathrm{bpm}$ & $64 \pm 2$ & $57 \pm 2 *$ & $120 \pm 3^{\dagger}$ & $118 \pm 3^{\dagger}$ \\
\hline SV, \% & $0 \pm 0$ & $11 \pm 3^{*}$ & $36 \pm 6^{\dagger}$ & $40 \pm 7^{* \dagger}$ \\
\hline Q, \% & $0 \pm 0$ & $-1 \pm 2$ & $157 \pm 16^{\dagger}$ & $161 \pm 16^{\dagger}$ \\
\hline $\mathrm{TPR}, \mathrm{mmHg} /(\mathrm{L} / \mathrm{min})$ & $17.5 \pm 1.1$ & $18.8 \pm 1.1^{*}$ & $7.9 \pm 0.4^{\dagger}$ & $8.0 \pm 0.4^{\dagger}$ \\
\hline CVRi, $\mathrm{mmHg} /(\mathrm{cm} / \mathrm{s})$ & $1.69 \pm 0.10$ & $1.77 \pm 0.13^{*}$ & $1.78 \pm 0.09$ & $1.81 \pm 0.10$ \\
\hline $\mathrm{P}_{\mathrm{ET}} \mathrm{CO}_{2}, \mathrm{mmHg}$ & $44 \pm 1$ & $44 \pm 1$ & $49 \pm 1^{\dagger}$ & $49 \pm 1^{\dagger}$ \\
\hline RPE & - & - & $11 \pm 1$ & $12 \pm 1$ \\
\hline
\end{tabular}

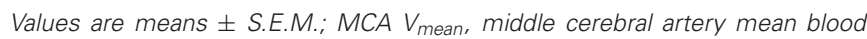
velocity; $S K B F_{\text {face }}$, forehead skin blood flow; MAP, mean arterial pressure; $H R$, heart rate; $S V$, stroke volume; $Q$, cardiac output; TPR, total peripheral resistance; $C V R i$, cerebrovascular resistance index; $P_{E T} C_{2}$, partial pressure of end tidal carbon dioxide; $R P E$, rating of perceived exertion. $* P<0.05$ different from baseline. ${ }^{\dagger} P<0.05$ different from rest.

unchanged (Table 2). In response to $\mathrm{FC}, \mathrm{SkBF}_{\text {face }}$ decreased and MCA $V_{\text {mean }}$, MAP, and SV increased at rest and during exercise. HR was decreased and TPR and CVRi were increased with FC at rest, but unchanged with FC during exercise. Q was unchanged with FC at rest and during exercise, but FC induced-change in $\mathrm{Q}$ tended to be higher during exercise $(P=0.08)$. $\mathrm{P}_{\mathrm{ET}} \mathrm{CO}_{2}$ was significantly increased during exercise but was unchanged with $\mathrm{FC}$ at the both conditions. RPE was not affected by FC during exercise.

The average MCA $V_{\text {mean }}$ was significantly increased by FC (Rest, $+1.4 \pm 0.5 \mathrm{~cm} / \mathrm{s}$; Exercise, $+1.4 \pm 0.6 \mathrm{~cm} / \mathrm{s}: \quad P<0.05$ ). However, the relation between the FC-evoked changes in MCA $V_{\text {mean }}$ at rest and during exercise differed among subjects; two subjects showed similar changes, three subjects showed larger responses during exercise; and four subjects showed smaller responses during exercise. The FC-induced decrease in $\mathrm{SkBF}_{\text {face }}$ was augmented during exercise compared with the resting condition $\left(\mathrm{SkBF}_{\text {face }}\right.$ : Rest, $-32 \pm 4 \%$; Exercise, $-64 \pm 10 \%, P=0.012$; Figures 1 and 2). MAP at rest and during exercise were increased by FC (Rest, $+6.2 \pm 1.4 \mathrm{mmHg}$; Exercise, $+4.2 \pm 1.2 \mathrm{mmHg}$, $P<0.05)$. However, the changes in MAP in response to FC were not different between at rest or during exercise $(P=0.13)$. The FC-induced decrease in HR and increase in SV were significantly attenuated during exercise compared with the resting condition (HR: Rest, $-6.8 \pm 1.5$ bpm; Exercise, $-1.8 \pm 1.1$ bpm, $P<0.05$; SV: Rest, $+11 \pm 3 \%$; Exercise, $+4 \pm 1 \%, P=0.015$, Figure 3 ). The FC-induced changes in $\mathrm{Q}$ were larger during exercise compared with the resting condition (Rest, $-1.0 \pm 1.5 \%$; Exercise, $+4.1 \pm 2.6 \%, P=0.08)$. The percent changes in MCA $V_{\text {mean }}$ induced by FC were not significantly correlated with the percent changes in $\mathrm{SkBF}_{\text {face }}(r=0.095, P=0.709)$.

\section{DISCUSSION}

The findings of the present study provide new information regarding $\mathrm{CBF}$ regulation to $\mathrm{FC}$ with water mist (FC) during dynamic exercise. As expected, FC was associated with an increase

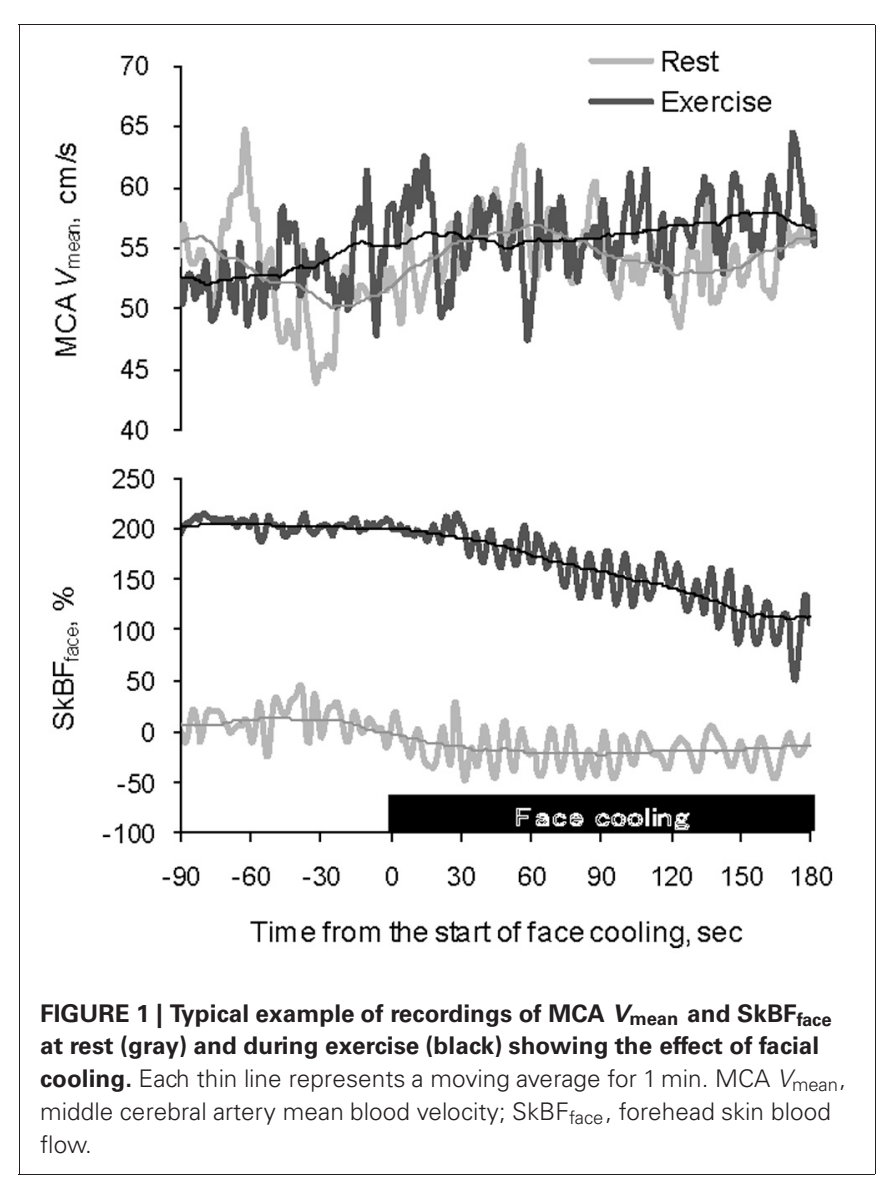

in MCA $V_{\text {mean }}$ at rest and during exercise. FC elicited a greater restriction of $\mathrm{SkBF}_{\text {face }}$ during exercise compared with the resting condition. However, this larger decrease in $\mathrm{SkBF}_{\text {face }}$ did not result in a larger increase in MCA $V_{\text {mean }}$ during exercise. In addition, changes in MCA $V_{\text {mean }}$ with the FC did not correlate with the concomitant changes in $\mathrm{SkBF}_{\text {face }}$. These findings suggest that other physiological mechanisms apart from decreased $\mathrm{SkBF}_{\text {face }}$, such as cardiovascular components of the diving reflex, may affect $\mathrm{CBF}$ during FC at least during mild dynamic exercise.

Anatomically, the ECA supplies blood to the face, anterior neck, and cranial surface. The ECA blood flow gradually increases with exercise intensity (Sato et al., 2011). In addition, this increase in ECA blood flow significantly correlates with the concomitant change in forehead cutaneous vascular conductance (Sato et al., 2011), suggesting that ECA blood flow is likely increased selectively for thermoregulatory purposes. Similarly, in the present study, $\mathrm{SkBF}_{\text {face }}$ was increased even during mild exercise as skin temperature rose. Moreover, selective $\mathrm{FC}$ decreased $\mathrm{SkBF}_{\text {face }}$ both at rest and during exercise (Table 2, Figures 1 and 2). This $\mathrm{SkBF}_{\text {face }}$ response may be due to a similar mechanism seen in the peripheral circulation, e.g., the local cooling-induced vasoconstriction (Johnson and Kellogg, 2010). As expected, the decrease in $\mathrm{SkBF}_{\text {face }}$ was significantly greater during exercise than that at rest $(P=0.012)$. These different $\mathrm{SkBF}_{\text {face }}$ responses may reflect an exercise-induced increase in facial capillary volume $(+132 \%$, $P=0.009)$ for thermoregulation rather than different autonomic 

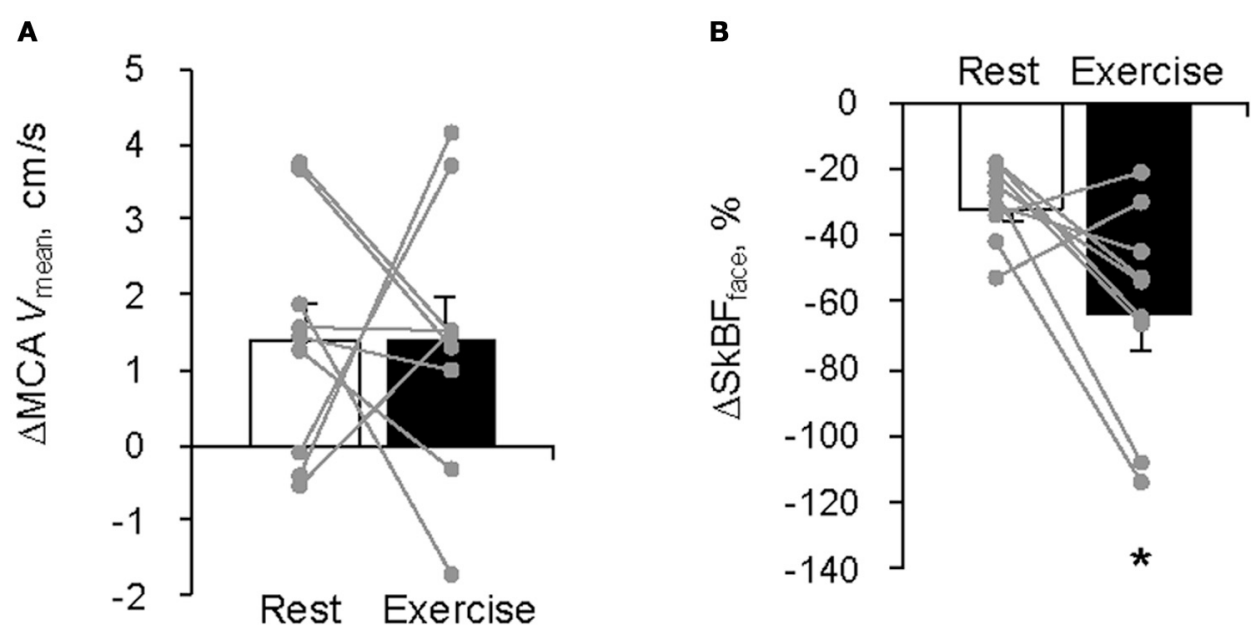

FIGURE 2 | Facial cooling-induced hemodynamic changes $(\Delta)$ at rest and during exercise: (A) middle cerebral artery mean blood velocity (MCA $\boldsymbol{V}_{\text {mean }}$ ) and $(\mathbf{B})$ forehead skin blood flow $\left(\mathbf{S k B F}_{\text {face }}\right)$. Each gray plot represents an individual response. Values are means $\pm \mathrm{S}$.E.M. ${ }^{*} P<0.05$ different from rest.
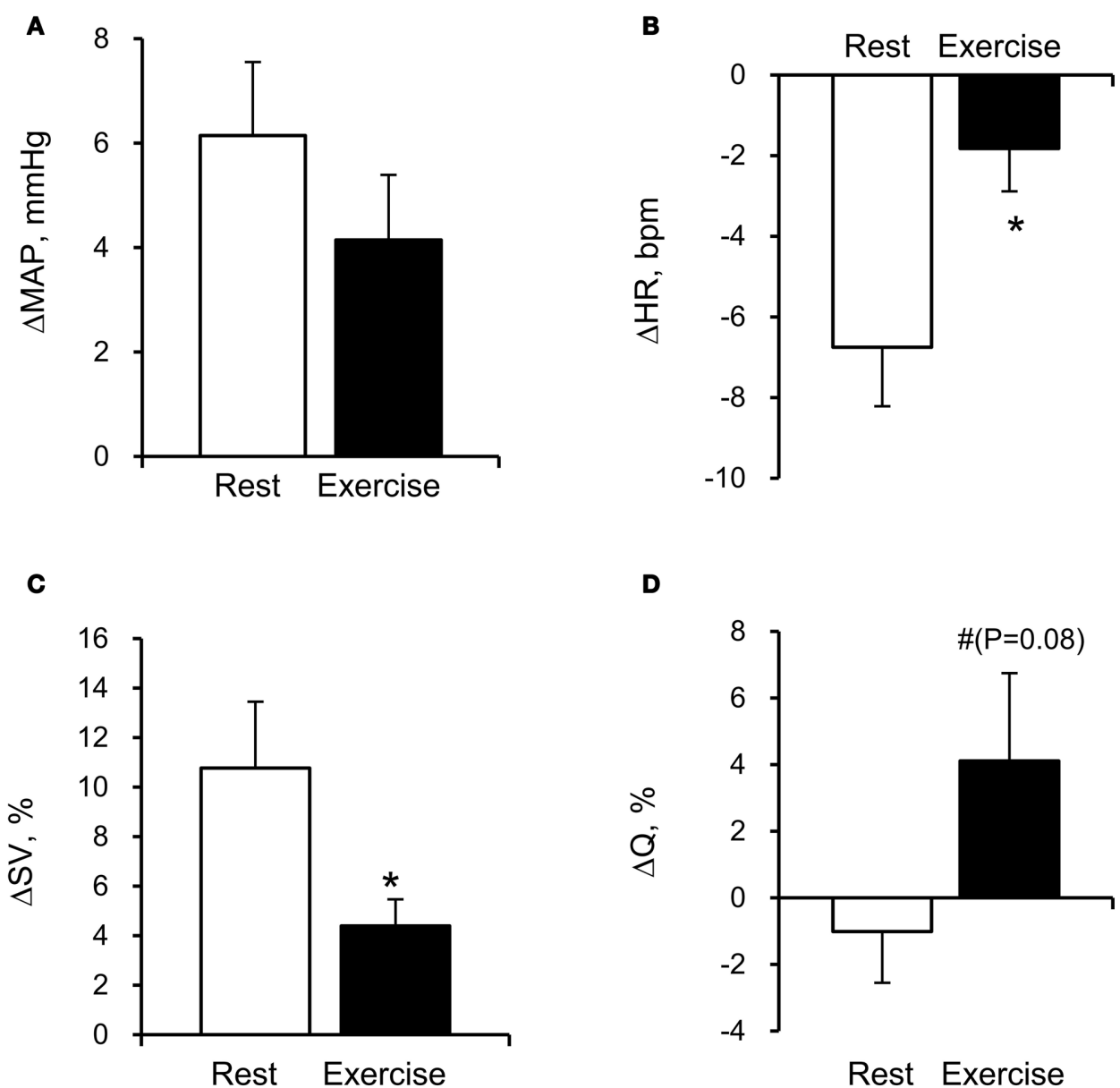

D

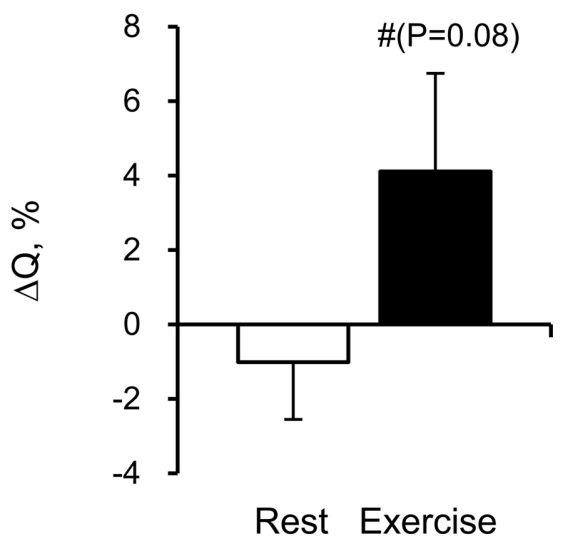

FIGURE 3 | Facial cooling-induced hemodynamic changes $(\Delta)$ at rest and during exercise: (A) mean arterial pressure (MAP), (B) heart rate (HR), (C) stroke volume (SV), and (D) cardiac output (Q). Values are means \pm S.E.M. ${ }^{*} P<0.05,{ }^{\#} P<0.1$ different from rest. 
regulation. In any case, these findings provide evidence that exercise-induced heat stress modifies the blood circulation in the head.

The common carotid artery bifurcates into the ECA and ICA; therefore, it is possible that changes in ECA blood flow could affect ICA flow and thus CBF. Indeed, during exercise changes in ECA blood flow were related to changes in ICA blood flow (Sato et al., 2011). Since fatigue and perception of effort during exercise may be related to CBF (Ide and Secher, 2000; Secher et al., 2008; Ogoh and Ainslie, 2009), we hypothesized that FC-induced effects on exercise time to fatigue (Ansley et al., 2008) and lowering of RPE (Mundel et al., 2007; Ansley et al., 2008) in the heat may have been associated with changes in blood flow to the face. In the present study, however, the FC-induced larger decreases in $\mathrm{SkBF}_{\text {face }}$ but did not lead to proportional changes in MCA $V_{\text {mean }}$ during exercise (Figure 2). Furthermore, there were no significant correlations between FC-induced changes in MCA $V_{\text {mean }}$ and $\mathrm{SkBF}_{\text {face }}$ at rest and during exercise $(P=0.709)$. These results suggest that the FC-induced increase in CBF could not be explained solely by changes in $\mathrm{SkBF}_{\text {face }}$ at least during mild exercise.

The interaction between facial blood flow and CBF may be mediated by factors associated with exercise intensity or the diving reflex. Sato et al. (2011) demonstrated that the increase in ECA blood flow from moderate to heavy intensity exercise was negatively correlated with the decrease in ICA blood flow. They suggested that a large increase in ECA blood flow contributes to the decrease in ICA blood flow observed during heavy exercise. In the present study, however, the relatively low exercise intensity and thermal stress may have been insufficient to cause significant diversion of blood from the brain (ICA) to the face (ECA). Indeed, FC did not change RPE during exercise in the present study despite an increase in MCA $V_{\text {mean }}$ (Table 2). During prolonged exercise at higher intensity or ambient temperature, the decrease in $\mathrm{CBF}$, perhaps due to diversion of blood to the face, may still influence the development of central fatigue (Nybo and Nielsen, 2001; Nybo et al., 2002; Dalsgaard et al., 2004). In these conditions, $\mathrm{SkBF}_{\text {face }}$ largely increases for thermoregulatory purposes and FC may attenuate facial vasodilatation and help preserve CBF.

Another possibility is that FC elicits the diving reflex in which facial cold receptors stimulate cardiovascular changes, including bradycardia and peripheral vasoconstriction (Fagius and Sundlof, 1986; Foster and Sheel, 2005; Kinoshita et al., 2006) that may divert blood toward the brain. For this to occur there would need to be a larger increase in peripheral relative to cerebral vascular resistance. Indeed, the increase in TPR was larger than CVRi at with $\mathrm{FC}$ at rest $(+7.4 \%$ vs. $+4.7 \%)$. Interestingly, this difference in the FC-induced change between TPR and CVRi was not evident during exercise $(+1.3 \%$ vs. $+1.7 \%)$. While CBF is generally believed to be maintained within a narrow range despite changes in MAP between 60 and $150 \mathrm{mmHg}$ - commonly known as cerebral autoregulation (Lassen, 1959). Lucas et al. (2010) indicated that CBF closely follows pharmacological-induced changes in blood pressure in humans. Therefore, it is possible that the increase in MAP induced by FC might have affected the MCA
$V_{\text {mean }}$ response during exercise. Further studies are needed for confirming the possibility. Also, Q affects CBF at rest and during exercise (Ogoh et al., 2005). In the present study, the changes in $\mathrm{Q}$ evoked by $\mathrm{FC}$ were negligible and not significant at rest and during exercise (Table 2). Therefore, it would appear that the changes in $\mathrm{Q}$ had a small effect on the FC-induced increase in $\mathrm{CBF}$. However, higher $\mathrm{Q}$ response to $\mathrm{FC}(P=0.08)$ may contribute to increase in MCA $V_{\text {mean }}$ during exercise. In addition, the diving reflex to FC enhances cardiac parasympathetic nerve activity via activation of facial receptors and the trigeminal nerve pathways (Heistad et al., 1968; Khurana et al., 1980). In the present study, FC decreased HR at rest and during exercise. The parasympathetic system has a potential vasodilator effect on brain vessels by mediators such as vasoactive intestinal peptide, acetylcholine, and nitric oxide (Hamel, 2006). More recently, it has been demonstrated that parasympathetic involvement might have a vasodilatory role in the regulation of the cerebral resistance vessels during mild dynamic exercise in humans (Seifert et al., 2010). Thus, it is likely that the increase in CBF evoked by FC might be associated with parasympathetic activation. However, $\mathrm{HR}$ responses to FC were different between rest and exercise. Taken together, the relative distribution of blood flow between the brain and the face appears to be regulated by different mechanisms depending on the level of exercise intensity and thermal stressors.

The present study involves some technical considerations. First, the transcranial Doppler ultrasonography-derived MCA $V_{\text {mean }}$ is an index of regional CBF, and it is acknowledged that this estimate is justified as a measure of CBF only if the vessel diameter is maintained (Valdueza et al., 1997; Serrador et al., 2000). However, the MCA diameter appears to change little during several conditions such as acute hemodynamic perturbations (Giller et al., 1993) and increases in sympathetic activity (Serrador et al., 2000). Additionally, the changes in MCA $V_{\text {mean }}$ during submaximal dynamic exercise appears to reflect transient changes in $\mathrm{CBF}$ determined by other exercise validated techniques [e.g., internal carotid artery blood flow (Hellstrom et al., 1996) and ${ }^{133}$ Xe clearance technique (Jorgensen et al., 1992a,b)]. Second, we used laser Doppler flowmetry to estimate the change in skin blood flow at the forehead. Although this method was used and validated in previous studies for estimation of flow changes in cutaneous regions, this technique has some acknowledged limitations, most notably the inability to provide quantitative measurements of $\mathrm{SkBF}_{\text {face }}$ in absolute units (Johnson et al., 1984). Therefore, we conducted the rest and exercise trials in the same day and did not move the laser Doppler probes throughout whole experiment to provide quantitative metrics for our comparisons. Finally, the protocol was not designed to identify the mechanism of $\mathrm{FC}$ induced-increases in CBF. It is possible that FC-induced hemodynamic changes (i.e., blood pressure) might modify the effects on $\mathrm{SkBF}_{\text {face }}$ and $\mathrm{CBF}$ regulation. Also, it is possible that the contribution of $\mathrm{SkBF}_{\text {face }}$ to FC induced-changes in MCA $V_{\text {mean }}$ was altered by exercise itself. Therefore, to address the actual mechanism of FC induced-increases in CBF, further studies, which manipulate $\mathrm{SkBF}_{\text {face }}$ without altering systemic circulation, will be needed. 


\section{SUMMARY}

FC evokes reflexes that reduce $S k B F_{\text {face }}$ at rest and to a greater extent during exercise. However, this larger decrease in $\mathrm{SkBF}_{\text {face }}$ did not result in a larger increase in MCA $V_{\text {mean }}$ during exercise. Because changes in $\mathrm{SkBF}_{\text {face }}$ did not correlate with changes in MCA $V_{\text {mean }}$, FC induced increases in MCA $V_{\text {mean }}$ during exercise could not be explained solely by changes in $\mathrm{SkBF}_{\text {face }}$. These results suggest that regulation of skin blood flow during low-intensity

\section{REFERENCES}

Ansley, L., Marvin, G., Sharma, A., Kendall, M. J., Jones, D. A., and Bridge, M. W. (2008). The effects of head cooling on endurance and neuroendocrine responses to exercise in warm conditions. Physiol. Res. 57, 863-872.

Borg, G. A. (1982). Psychophysical bases of perceived exertion. Med. Sci. Sports Exerc. 14, 377-381.

Brown, C. M., Sanya, E. O., and Hilz, M. J. (2003). Effect of cold face stimulation on cerebral blood flow in humans. Brain Res. Bull. 61, 81-86.

Dalsgaard, M. K., Ogoh, S., Dawson, E. A., Yoshiga, C. C., Quistorff, B., and Secher, N. H. (2004). Cerebral carbohydrate cost of physical exertion in humans. Am. J. Physiol. Regul. Integr. Comp. Physiol. 287, R534-R540.

Fagius, J., and Sundlof, G. (1986). The diving response in man: effects on sympathetic activity in muscle and skin nerve fascicles. J. Physiol. 377, 429-443.

Foster, G. E., and Sheel, A. W. (2005). The human diving response, its function, and its control. Scand. J. Med. Sci. Sports 15, 3-12.

Giller, C. A., Bowman, G., Dyer, H., Mootz, L., and Krippner, W. (1993). Cerebral arterial diameters during changes in blood pressure and carbon dioxide during craniotomy. Neurosurgery 32, 737-741. discussion: 741-732.

Hamel, E. (2006). Perivascular nerves and the regulation of cerebrovascular tone. J. Appl. Physiol. 100, 1059-1064.

Heistad, D. D., Abbound, F. M., and Eckstein, J. W. (1968). Vasoconstrictor response to simulated diving in man. J. Appl. Physiol. 25, 542-549.

Hellstrom, G., Fischer-Colbrie, W., Wahlgren, N. G., and Jogestrand, T. (1996). Carotid artery blood flow and middle cerebral artery blood flow velocity during physical exercise. J. Appl. Physiol. 81, $413-418$.
Ide, K., and Secher, N. H. (2000). Cerebral blood flow and metabolism during exercise. Prog. Neurobiol. 61, 397-414.

Johnson, J. M., and Kellogg, D. L. Jr. (2010). Local thermal control of the human cutaneous circulation. $J$. Appl. Physiol. 109, 1229-1238.

Johnson, J. M., Taylor, W. F., Shepherd, A. P., and Park, M. K. (1984). LaserDoppler measurement of skin blood flow: comparison with plethysmography. J. Appl. Physiol. 56, 798-803.

Jorgensen, L. G., Perko, G., and Secher, N. H. (1992a). Regional cerebral artery mean flow velocity and blood flow during dynamic exercise in humans. J. Appl. Physiol. 73, 1825-1830.

Jorgensen, L. G., Perko, M., Hanel, B., Schroeder, T. V., and Secher, N. H. (1992b). Middle cerebral artery flow velocity and blood flow during exercise and muscle ischemia in humans. J. Appl. Physiol. 72, 1123-1132.

Khurana, R. K., Watabiki, S., Hebel, J. R., Toro, R., and Nelson, E. (1980). Cold face test in the assessment of trigeminal-brainstem-vagal function in humans. Ann. Neurol. 7, 144-149.

Kinoshita, T., Nagata, S., Baba, R., Kohmoto, T., and Iwagaki, S. (2006). Cold-water face immersion per se elicits cardiac parasympathetic activity. Circ. J. 70, 773-776.

Kjeld, T., Pott, F. C., and Secher, N. H. (2009). Facial immersion in cold water enhances cerebral blood velocity during breath-hold exercise in humans. J. Appl. Physiol. 106, 1243-1248.

Lassen, N. A. (1959). Cerebral blood flow and oxygen consumption in man. Physiol. Rev. 39, 183-238.

Lucas, S. J., Tzeng, Y. C., Galvin, S. D., Thomas, K. N., Ogoh, S. and Ainslie, P. N. (2010). Influence of changes in blood pressure on cerebral perfusion and oxygenation. Hypertension 55, 698-705.

exercise has little impact on overall CBF and those other mechanisms.

\section{ACKNOWLEDGMENTS}

We appreciate the time and effort spent by our volunteer subjects. This study was supported by the Center for Academic Researches Promotion (Toyo University Research Institution of Industrial Technology, Grant \#7).

Mundel, T., Bunn, S. J., Hooper, P. L., and Jones, D. A. (2007). The effects of face cooling during hyperthermic exercise in man: evidence for an integrated thermal, neuroendocrine and behavioural response. Exp. Physiol. 92, 187-195.

Nybo, L., Moller, K., Volianitis, S. Nielsen, B., and Secher, N. H (2002). Effects of hyperthermia on cerebral blood flow and metabolism during prolonged exercise in humans. J. Appl. Physiol. 93, 58-64.

Nybo, L., and Nielsen, B. (2001). Middle cerebral artery blood velocity is reduced with hyperthermia during prolonged exercise in humans. J. Physiol. 534, 279-286.

Ogoh, S., and Ainslie, P. N. (2009). Cerebral blood flow during exercise: mechanisms of regulation. J. Appl. Physiol. 107, 1370-1380.

Ogoh, S., Brothers, R. M., Barnes, Q. Eubank, W. L., Hawkins, M. N., Purkayastha, S., O-Yurvati, A., and Raven, P. B. (2005). The effect of changes in cardiac output on middle cerebral artery mean blood velocity at rest and during exercise. J. Physiol. $569,697-704$

Ramanathan, N. L. (1964). A new weighting system for mean surface temperature of the human body. $J$. Appl. Physiol. 19, 531-533.

Sato, K., Ogoh, S., Hirasawa, A., Oue, A., and Sadamoto, T. (2011). The distribution of blood flow in the carotid and vertebral arteries during dynamic exercise in humans. $J$. Physiol. 589, 2847-2856.

Secher, N. H., Seifert, T., and Van Lieshout, J. J. (2008). Cerebral blood flow and metabolism during exercise: implications for fatigue. J. Appl. Physiol. 104, 306-314.

Seifert, T., Fisher, J. P., Young, C. N., Hartwich, D., Ogoh, S., Raven, P. B., Fadel, P. J., and Secher, N. H. (2010). Glycopyrrolate abolishes the exercise-induced increase in cerebral perfusion in humans. Exp. Physiol. 95, 1016-1025.

Serrador, J. M., Picot, P. A., Rutt, B. K., Shoemaker, J. K., and Bondar,
R. L. (2000). MRI measures of middle cerebral artery diameter in conscious humans during simulated orthostasis. Stroke 31, 1672-1678

Sugawara, J., Tanabe, T., Miyachi, M., Yamamoto, K., Takahashi, K., Iemitsu, M., Otsuki, T., Homma, S. Maeda, S., Ajisaka, R., and Matsuda, M. (2003). Non-invasive assessment of cardiac output during exercise in healthy young humans: comparison between Modelflow method and Doppler echocardiography method. Acta Physiol. Scand. 179, 361-366.

Valdueza, J. M., Balzer, J. O., Villringer, A., Vogl, T. J., Kutter, R., and Einhaupl, K. M. (1997). Changes in blood flow velocity and diameter of the middle cerebral artery during hyperventilation: assessment with MR and transcranial Doppler sonography. AJNR Am. J. Neuroradiol. 18, 1929-1934.

Conflict of Interest Statement: The authors declare that the research was conducted in the absence of any commercial or financial relationships that could be construed as a potential conflict of interest.

Received: 13 March 2012; accepted: 13 July 2012; published online: 02 August 2012.

Citation: Miyazawa $T$, Horiuchi $M$ Ichikawa D, Subudhi AW, Sugawara J and Ogoh S (2012) Face cooling with mist water increases cerebral blood flow during exercise: effect of changes in facial skin blood flow. Front. Physio. 3:308. doi: 10.3389/fphys.2012.00308

This article was submitted to Frontiers in Exercise Physiology, a specialty of Frontiers in Physiology.

Copyright (c) 2012 Miyazawa, Horiuchi, Ichikawa, Subudhi, Sugawara and Ogoh. This is an open-access article distributed under the terms of the Creative Commons Attribution License, which permits use, distribution and reproduction in other forums, provided the original authors and source are credited and subject to any copyright notices concerning any third-party graphics etc. 